University of Nebraska - Lincoln

DigitalCommons@University of Nebraska - Lincoln

Educational Psychology Papers and

Publications

Educational Psychology, Department of

2015

Relations Between Intimate Partner Violence and Forgiveness Among College Women

\author{
M. Meghan Davidson \\ University of Nebraska-Lincoln, mdavidson2@unl.edu \\ Nicole M Lozano \\ University of Nebraska-Lincoln \\ Brian P. Cole \\ Seton Hall University, bricole@ku.edu \\ Sarah Gervais \\ University of Nebraska-Lincoln, sgervais2@unl.edu
}

Follow this and additional works at: https://digitalcommons.unl.edu/edpsychpapers

Part of the Child Psychology Commons, Cognitive Psychology Commons, Developmental Psychology Commons, and the School Psychology Commons

Davidson, M. Meghan; Lozano, Nicole M; Cole, Brian P.; and Gervais, Sarah, "Relations Between Intimate Partner Violence and Forgiveness Among College Women" (2015). Educational Psychology Papers and Publications. 205.

https://digitalcommons.unl.edu/edpsychpapers/205

This Article is brought to you for free and open access by the Educational Psychology, Department of at DigitalCommons@University of Nebraska - Lincoln. It has been accepted for inclusion in Educational Psychology Papers and Publications by an authorized administrator of DigitalCommons@University of Nebraska - Lincoln. 
Published in Journal of Interpersonal Violence 30:18 (2015), pp. 3217-3243. doi 10.1177/0886260514555008

Copyright (c) 2014 M. Meghan Davidson, Nicole M. Lozano, Brian P. Cole, and Sarah J. Gervais; published by SAGE Publications. Used by permission.

\title{
Relations Between Intimate Partner Violence and Forgiveness Among College Women
}

\author{
M. Meghan Davidson, $\mathrm{PhD},{ }^{1}$ Nicole M. Lozano, $\mathrm{MA}^{1}{ }^{1}$ \\ Brian P. Cole, $\mathrm{PhD},{ }^{2}$ and Sarah J. Gervais, $\mathrm{PhD}$
}

\author{
1 University of Nebraska-Lincoln, Lincoln, NE, USA \\ 2 Seton Hall University, South Orange, NJ, USA
}
Corresponding author - M. Meghan Davidson, University of Nebraska-Lincoln, 114 Teachers College Hall, P.O. Box 880345, Lincoln, NE 68588-0345, USA; email mdavidson2@unl.edu

\begin{abstract}
The purpose of the current investigation was to examine forgiveness and intimate partner violence (IPV) among college women. Undergraduate women $(N=502)$ participated in an online study in which overall experiences of IPV, as well as experiences of psychological and physical IPV, were investigated with respect to transgression-specific and dispositional forgiveness. Simultaneous multivariate regressions revealed that (a) the experience of IPV was associated with higher levels of avoidance and revenge, and lower levels of benevolence, forgiveness of self, forgiveness of others, and forgiveness of uncontrollable situations; (b) types of IPV demonstrated differing impacts on forgiveness; and (c) the mere experience of IPV is more salient than its frequency.
\end{abstract}

Keywords intimate partner violence, forgiveness, avoidance, revenge, benevolence 
Intimate partner violence (IPV) is a serious and challenging societal problem. The Centers for Disease Control and Prevention (CDC) define IPV (also "domestic violence") as "threatened, attempted, or completed physical or sexual violence or emotional abuse by a current or former intimate partner. IPV can be committed by a spouse, an ex-spouse, a current or former boyfriend or girlfriend, or a dating partner" (CDC, National Center for Injury Prevention and Control, 2008). Regarding prevalence, recent studies show that $33 \%$ of women in the United States report experiencing physical abuse from an intimate partner during their lifetime, whereas $4.0 \%$ report such abuse in the past 12 months (Black et al., 2011; CDC, National Center for Injury Prevention and Control, 2010). As well, 48\% of women report experiencing psychological and emotional abuse from an intimate partner during their lifetime, whereas 14\% report such abuse during the past 12 months (Black et al., 2011). Regarding college-aged women, 35\% of respondents reported at least one instance of IPV victimization during college (Fass, Benson, \& Leggett, 2008).

Although statistics such as these are sobering, the field of Positive Psychology may provide an alternative lens through which to view IPV. Positive Psychology researchers have advocated for the study of positive individual traits and positive emotions (Seligman \& Csikszentmihalyi, 2000). Positive traits (e.g., hope, forgiveness, gratitude) may facilitate positive emotional experiences that build resilience and buffer against psychopathology and symptom distress (Magyar-Moe, 2009), as well as undo lingering negative emotions and build adaptive coping skills that serve as buffers against negative emotional experiences (Fredrickson, 1998, 2001, 2003; Fredrickson, Mancuso, Branigan, \& Tugade, 2000). One such positive trait, forgiveness, has been noted in the literature to be effective in resolving remorse, guilt, anger, anxiety, and fear (Cerney, 1988; Fitzgibbons, 1986). Given the numerous negative consequences associated with IPV, including anxiety, distrust of others, sleep disturbances, depression, and suicide risk (Felitti et al., 1998; Yuan, Koss, \& Stone, 2006), it is possible that IPV is also associated with decreased positive psychology variables as well, including forgiveness.

Of the limited previous studies that have focused on IPV and forgiveness, most have done so in reference to the specific intimate partner relationship. For example, Coop Gordon, Burton, and Porter (2004) found that women who were residing in domestic violence shelters demonstrated higher intentions to return to their abusive partner if they forgave that partner. Relatedly, in their study of undergraduate women in dating relationships and hypothetical IPV, Katz, Street, and Arias (1997) found that higher self-esteem was significantly associated with less intentions to forgive the IPV, and that higher self-attributions (i.e., blame of self for the IPV) were asso- 
ciated with more forgiveness and less intentions to exit the relationship. In addition, in a study of couples in which the male partner had been convicted of IPV and subsequently court-ordered to participate in an IPV intervention program, Tsangand Stanford (2007) found that the women IPV survivors' empathy toward their partner and overall religiosity was significantly associated with forgiveness of their partner. However, blaming their partners for the IPV was not associated with any forgiveness attributes, including revenge (Tsang \&Stanford, 2007). Finally, in a longitudinal study of couples, McNulty (2011)found that partners who were forgiving of both psychological and physical IPV were more likely to continue experiencing that aggression from their partner.

Building on and complementing these findings, we provide the novel suggestion that the experience of IPV may be associated with less forgiving dispositions more generally. The implications of this relation could be considerable, given that forgiveness may serve as a buffer against symptom distress and trauma related to IPV and other life stressors (Cerney, 1988;Felitti et al., 1998; Fitzgibbons, 1986; Yuan et al., 2006). However, scanter search examining the role of forgiveness with respect to IPV has been conducted to date. Thus, the purpose of the current study was to explore associations between IPV and forgiveness among a sample of college women.

Researchers have offered various conceptualizations of forgiveness, including emotional, cognitive, and behavioral components (e.g., Cosgrove\& Konstam, 2008; Enright, Eastin, Golden, Sarinopoulos, \& Freedman,1992; Witvliet, 2003). Transgression-specific (McCullough, 2000) and dispositional(Thompson et al., 2005) considerations of forgiveness have also been offered, and were the focus of the current study as these have been operationalized into psychometrically valid measures (i.e., the Transgression-Related Interpersonal Motivations (TRIM) Scale [McCullough et al., 1998] and the Heartland Forgiveness Scale [HFS; Thompson et al., 2005]). It is important to note that forgiveness does not mean condoning or excusing a wrong doing (e.g., Freedman, 1998).

McCullough (2000) describes transgression-specific forgiveness as denoted by a diminished desire to avoid and/or to hurt the transgressor, and a heightened desire to behave more positively toward the transgressor. WhileMcCullough's (2000) view of forgiveness is specific to a particular transgressor, Thompson and colleagues (2005) posit a dispositional conceptualization of forgiveness, which encompasses a more holistic view, including forgiveness of oneself, other individuals, and uncontrollable situations (e.g., natural disasters, trauma). Whereas McCullough (2000) and others (e.g., Enright \&Fitzgibbons, 2000) propose responding to a wrongdoer with respect to moral principles of compassion and generosity, Thompson et al. (2005) depict forgiveness as reframing a wrongdoing from a negative per- 
spective to either neutral or positive without a focus on feelings or cognitions toward the wrong doer. Thus, in the case of IPV, the emphasis would be on reframing experiences of IPV rather than changing feelings or cognitions toward the transgressor.

To date, research on forgiveness has focused mainly on investigating its benefits and consequences, as well as its predictors (see McCullough, Root, Tabak, \& Witvliet, 2009, for an overview). For example, Thompson and colleagues(2005) suggest that forgiveness leads to healthier lifestyles, higher self-esteem, less depression and anxiety, and more hope. Further, individuals who are more forgiving have been shown to demonstrate higher levels of well-being and fewer negative physical health symptoms (Brown, 2003), lower levels of depression and anxiety (Thompson et al., 2005), and more positive interpersonal relationships (McCullough et al., 1998). McCulloughand Hoyt (2002) linked personality variables such as neuroticism, agreeableness, narcissism, and religiousness as personality traits that predict varying levels of forgiveness. The present work extends this latter work to consider potential associations between IPV and forgiveness.

\section{The Current Study}

Given what is known about the benefits of forgiveness overall and the consequences of IPV, it becomes apparent that understanding dimensions of forgiveness for those who have been victimized is essential. To date, sparse research has explored the relations between forgiveness and the experience of IPV, and the scant research that has been conducted has focused specifically on the immediate partner relationship (Coop Gordon et al., 2004; Katz et al.,1997; McNulty, 2011; Tsang \& Stanford, 2007). Thus, the present study aimed to explore the associations of forgiveness and IPV more broadly. If the experience of IPV alters women's general forgiveness orientations, this may have considerable consequences for relations with future intimate partners, as well as family, friends, colleagues, and mental health professionals.

Overall, the study examined whether experiences of IPV among college women are associated with (a) more or less forgiveness toward a specific transgressor and (b) more or less forgiveness more generally toward other people, as well as additional entities including the self and uncontrollable situations. Being abused in the context of an intimate partner relationship, as well as the frequency with which these experiences occurred, should lead to less motivation to forgive specific transgressors as well as an overall less forgiving orientation. Similarly, differing types of IPV (i.e., psychological, physical) may be uniquely associated with motivation to forgive transgres- 
sors as well as forgiveness of the self, others, and uncontrollable situations (Gervais \& Davidson, 2013). The current investigation did not focus specifically on motivations to forgive the intimate partner who perpetrated the abuse because previous research has examined these relations (Coop Gordon et al., 2004; Katz et al., 1997; McNulty, 2011; Tsang \& Stanford, 2007). Instead, the current study extended previous work, examining forgiveness more broadly in relation to IPV.

Transgression-specific forgiveness (McCullough, 2000) and dispositional forgiveness (Thompson et al., 2005) were assessed in the current study as operationalized by the measures used. Research suggests that previously stable traits can be impacted by traumatic experiences (for reviews, see Falsetti, Resick, \& Davis, 2003; Linley \& Joseph, 2004; Tedeschi \& Calhoun, 2004); thus, the current study included an examination of changes to both state and dispositional levels of forgiveness. First, interpersonal motivations toward a transgressor of a specific transgression, including avoidance, revenge, and benevolence were examined. The experience of IPV is associated with distrust of others and strained relationships (Clements, Speck, Crane, \& Faulkner, 2004; Felitti et al., 1998; Golding, Wilsnack, \& Cooper, 2002; Yuan et al., 2006), and thus, it was hypothesized that experiencing IPV would be associated with less motivation toward transgression specific forgiveness. Second, dispositional forgiveness toward the self, others, and uncontrollable situations were examined. Given previous research demonstrating that the experience of IPV is associated with higher levels of shame (Rhatigan, Shorey, \& Nathanson, 2011; Spangaro, Zwi, \& Poulos, 2011), lower levels of trust in others (Felitti et al., 1998; Yuan et al., 2006), and loss of power and control (Dutton \& Goodman, 2005; Stark, 2007), it was hypothesized that experiencing IPV would be associated with less dispositional forgiveness.

In addition, researchers are beginning to explore the potential unique contributions of various types of IPV to a variety of psychological experiences. For example, psychological IPV has been shown to uniquely predict symptoms of depression and posttraumatic stress disorder (Mechanic, Weaver, \& Resick, 2008), whereas psychological IPV has proved to be an equally strong a predictor of negative health outcomes as physical IPV in a variety of studies (Becker, Stuewig, \& McCloskey, 2010; Coker, Smith, McKeown, \& King, 2000; Pico-Alfonso et al., 2006; T. P. Sullivan, McPartland, Armeli, Jaquier, \& Tennen, 2012). More recently, psychological IPV demonstrated stronger associations with self-objectification, body surveillance, and body shame as compared with physical IPV in a sample of college women (Gervais \& Davidson, 2013). Therefore, the unique predictors of psychological IPV and physical IPV on forgiveness were examined. 


\section{Specific Hypotheses}

We examined the aforementioned hypotheses with respect to simply experiencing IPV (or not) as well as the frequency of these experiences on transgression- related and dispositional forgiveness. It is possible that more frequent experiences of IPV are associated with less forgiveness. It is also possible that simply experiencing IPV or not (regardless of the frequency of experiences) is associated with less forgiving orientations. We used a two pronged approach to consider these questions. First, we examined the relations between general experiences of IPV and forgiveness employing four multiple regression models. Specifically, the following hypotheses were evaluated:

Hypothesis 1: Experiencing IPV, as assessed dichotomously, will be associated with transgression-related forgiveness. More specifically, experiencing (vs. not experiencing) IPV will be associated (1a) positively with avoidance, (1b) positively with revenge, and (1c) negatively with benevolence.

Hypothesis 2: Experiencing IPV, as assessed dichotomously, will be associated with dispositional forgiveness. More specifically, experiencing (vs. not experiencing) IPV will be associated (2a) negatively with forgiveness of self, (2b) negatively with forgiveness of others, and (2c) negatively with forgiveness of uncontrollable situations.

Hypothesis 3: The frequency of experiencing IPV will be associated with transgression-related forgiveness; a greater frequency of experiencing IPV will be associated (3a) positively with avoidance, (3b) positively with revenge, and (3c) negatively with benevolence.

Hypothesis 4: The frequency of experiencing IPV will be associated with dispositional forgiveness; a greater frequency of experiencing IPV will be associated (4a) negatively with forgiveness of self, (4b) negatively with forgiveness of others, and (4c) negatively with forgiveness of uncontrollable situations.

Second, because psychological and physical IPV have shown differential associations to outcomes, we examined the unique effects of both types of IPV on transgression-specific and general forgiveness in four additional regression models. This extends Hypotheses 1 to 4 to consider the potential relations to forgiveness uniquely explained by psychological and physical IPV. We made specific predictions regarding psychological IPV and forgiveness, given the aforementioned research regarding associations of psychological IPV with numerous negative outcomes (e.g., Becker et al., 2010; 
Gervais \& Davidson, 2013; T. P. Sullivan et al., 2012), and only examined physical IPV in an exploratory manner.

Hypothesis 5: Experiencing (vs. not experiencing) psychological IPV will be associated with transgression-related forgiveness. More specifically, experiencing psychological IPV will be associated (5a) positively with avoidance, (5b) positively with revenge, and (5c) negatively with benevolence.

Hypothesis 6: Experiencing (vs. not experiencing) psychological IPV will be associated with dispositional forgiveness. More specifically, experiencing psychological IPV will be associated (6a) negatively with forgiveness of self, (6b) negatively with forgiveness of others, and (6c) negatively with forgiveness of uncontrollable situations.

Hypothesis 7: The frequency of experiencing psychological IPV will be associated with transgression-related forgiveness. That is, a greater frequency of experiencing psychological IPV will be associated (7a) positively with avoidance, (7b) positively with revenge, and (7c) negatively with benevolence.

Hypothesis 8: The frequency of experiencing psychological IPV will be associated with dispositional forgiveness. That is, a greater frequency of experiencing psychological IPV will be associated (8a) negatively with forgiveness of self, (8b) negatively with forgiveness of others, and (8c) negatively with forgiveness of uncontrollable situations.

\section{Method}

\section{Participants}

A total of 572 undergraduate women from a large, Midwestern university participated in this study. After accounting for invalid data (see below), 502 participants were included in the final data set. Participant ages ranged from 17 to 38 years $(M=19.89, S D=2.09)$. Regarding racial demographics, the majority described themselves as White (88\%). Biracial or multiracial women constituted $4 \%$ of the sample, and 3\% were Asian American, 2\% were Latino, 2\% were African American, 0.2\% were Native American, and $0.2 \%$ designated "Other."

\section{Procedures and Instruments}

Institutional Review Board approval was obtained prior to study recruitment. Students from undergraduate psychology courses and sorority chap- 
ters were recruited to participate in the study. More specifically, (a) the study was listed as an opportunity on the participant pool website of the psychology department, and (b) the first author discussed the study with sorority chapter presidents who in turn informed their members about the opportunity to participate in the study. It is not possible to determine the total number of undergraduate women who had access to the study invitation; thus, the participation rate cannot be calculated. Information provided to potential participants included that the online research examined psychology, life experiences, and violence, and that some sensitive items would be asked. Participants provided electronic, informed consent and completed the instruments with order counterbalanced online via Survey Monkey. Validity items (e.g., "Please answer 'mildly' for this item”) were interspersed throughout the survey, and data were deemed invalid and excluded from analyses if participants responded incorrectly to these items. Entry into a \$20 gift certificate raffle or course credit was offered as compensation for participation.

TRIM 18-R (McCullough et al., 1998) is an 18-item scale that measures levels of forgiveness for a specific transgression that is determined by the participant (i.e., "For the items on this page, please think about the person who has hurt you in the most significant way"). The TRIM 18-R is comprised of three subscales: (a) Avoidance, (b) Revenge, and (c) Benevolence. The seven-item Avoidance subscale (e.g., "I am living as if he/she doesn't exist, isn't around") measures motivation to evade a transgressor, whereas the fiveitem Revenge subscale (e.g., "I'm going to get even") assesses motivation to seek vengeance, and the six-item Benevolence subscale (e.g., "I have released my anger so I can work on restoring our relationship to health") measures motivation toward compassion for the transgressor. Items are rated on a 5-point Likert-type scale ranging from 1 (strongly disagree) to 5 (strongly agree), and subscales scores are summed. A total score on the TRIM 18-R Scale is not utilized (McCullough et al., 1998). All subscales have demonstrated adequate internal consistency reliability ( $\alpha \geq$.85), moderate 8-week test-retest reliability $(r \geq .50)$, and evidence of construct validity (McCullough et al., 1998). For the current study, the TRIM 18-R subscale scores demonstrated good internal consistency reliability with $\alpha=.93, .86$, and .88 for Avoidance, Revenge, and Benevolence, respectively. See Table 1 for means and standard deviations for all subscales.

HFS (Thompson et al., 2005) is an 18-item self-report instrument measuring forgiveness in three domains: (a) forgiveness of self (e.g., "With time I am understanding of myself for mistakes I've made”), (b) forgiveness of others (e.g., "Although others have hurt me in the past, I have eventually been able to see them as good people"), and (c) forgiveness of uncontrollable situations (e.g., "It's really hard for me to accept negative situations 


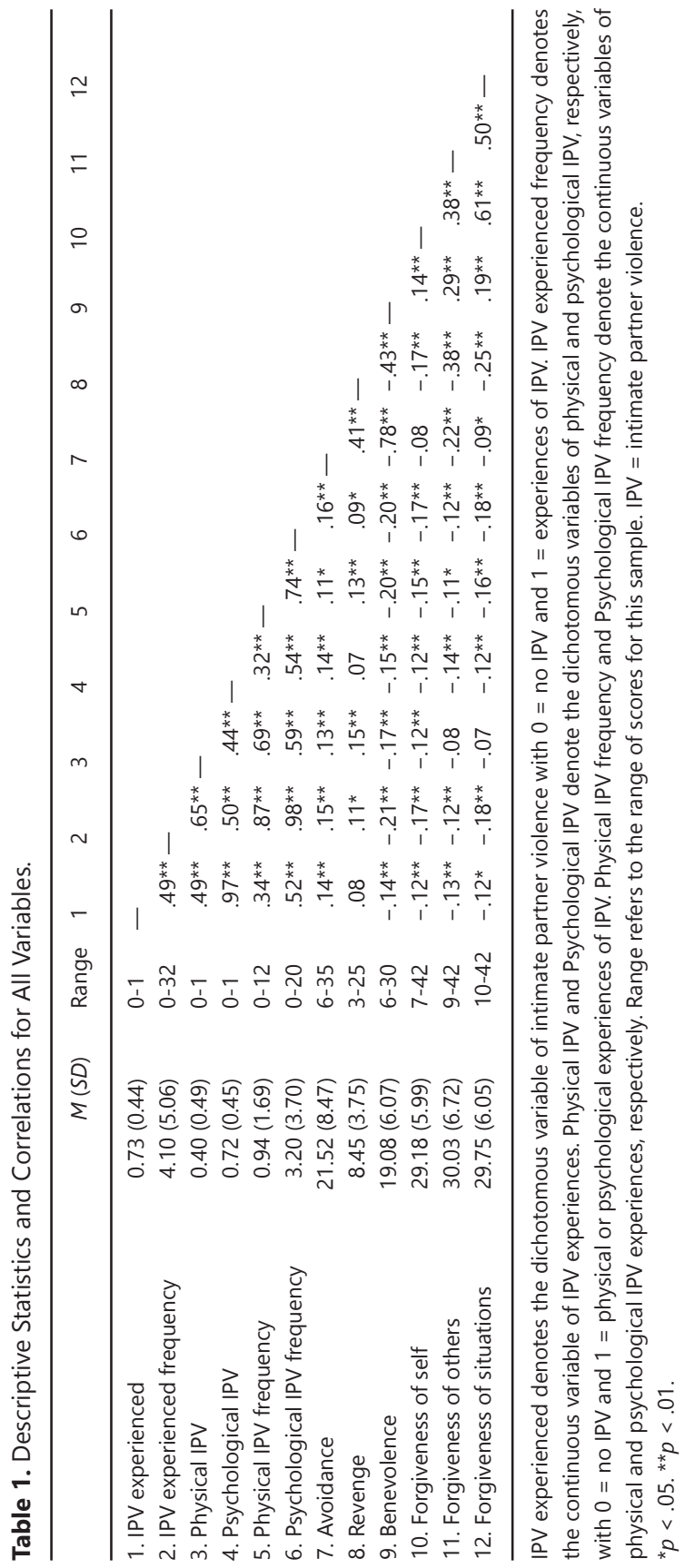


that aren't anybody's fault"). These domains are assessed on three six-item subscales, respectively. Items are rated on a 7-point Likert-type scale ranging from 1 (almost always false of me) to 7 (almost always true of me), and subscales scores and a total score are summed. Satisfactory internal consistency reliability has been demonstrated for both the total score $(\alpha=.84$ to .87) and subscale scores ( $\alpha=.71$ to .83 ; Thompson \& Snyder, 2003). Thompson et al. (2005) reported adequate 3-week test-retest reliability for HFS Others $(r=.73)$ and HFS Self $(r=.72)$, and adequate 9-month testretest reliability for both subscales $(r=.69)$. Concurrent validity has been demonstrated using the TRIM 18-R and the Enright Forgiveness Inventory (Thompson et al., 2005). For the current study, the HFS subscales demonstrated adequate internal consistency reliability (Self: $\alpha=.78$, Others: $\alpha=.85$, Situations: $\alpha=.79$ ). See Table 1 for means and standard deviations for all subscales.

Abusive Behavior Inventory-Partner Form (ABI-PF; Shepard \& Campbell, 1992) assesses the frequency of abusive behaviors experienced in the last 6 months in the context of an intimate relationship. The 30-item inventory measures abusive behaviors in both psychological and physical domains; these domains correspond to the two subscales of the ABI-PF. Items are rated in terms of frequency of experiencing particular behaviors using a 5-point Likert scale ranging from 1 (never) to 5 (very frequently). Among adult men and women, internal consistency reliability for the total scale has been demonstrated to range from $\alpha=.70$ to .92 , with internal consistency reliability for the physical abuse subscale ranging from $\alpha=.80$ to .92 , and the psychological abuse subscale ranging from $\alpha=.76$ to .91 (Shepard \& Campbell, 1992). The ABI-PF has also been examined in relation to clinical assessments of abuse, client assessments of abuse, and prior arrest for domestic abuse, all evidencing good construct validity (Shepard \& Campbell, 1992). Previous researchers have adapted the ABI-PF for the particular purposes of their investigations (e.g., Mills \& Malley-Morrison, 1998; Yorke, Friedman, \& Hurt, 2010). Similarly, for the current investigation's purposes, the ABI-PF included 8 items demonstrative of psychological and physical abuse (Gervais \& Davidson, 2013). The selected items were those that exhibited the highest item-factor loadings and those that characterized a range of psychological and physical abuse on the ABI-PF (Shepard \& Campbell, 1992): "called you names and/or criticized you"; "tried to keep you from doing something you wanted to do (examples: going out with friends, going to meetings)"; "threatened to hit or throw something at you"; "pushed, grabbed, or shoved you"; "said things to scare you (examples: told you something bad would happen, threatened to commit suicide)"; "slapped, hit, punched, or kicked you"; "checked up on you (examples: listened to your phone calls, checked the mileage on your car, called you repeatedly 
at work)"; and "pressured you to have sex in a way that you didn't like or want.” Consistent with prior research (e.g., Burch \& Gallup, 2000; Neufeld, McNamara, \& Ertl, 1999), participants responded to each item with regard to their entire dating history. For the current study, the modified total ABIPF demonstrated good internal consistency reliability $(\alpha=.88)$, as did the modified psychological abuse subscale $(\alpha=.84)$ and the modified physical abuse subscale $(\alpha=.71)$. It is important to note, however, that abusers might not employ every tactic assessed on the ABI-PF; thus, the internal consistency reliability should be interpreted such that survivors may only experience a few types of specific abuse from their partners (e.g., experienced threats, name calling, and slapping, but not pressure to have sex or being checked up on).

The following variables were created from the ABI-PF items. First, a dichotomous variable was produced to compare participants who endorsed items on the ABI-PF and those who did not as an indicator of experiencing IPV (or not). Second, a variable representing the total frequency of abusive experiences was created by summing the items on the ABI-PF. Third, two dichotomous variables were created for psychological IPV and physical IPV to indicate those participants who experienced psychological IPV (or not) and those who experienced physical IPV (or not). Finally, two variables representing the frequency of psychological IPV and the frequency of physical IPV were created by summing the respective subscale items on the ABI-PF.

\section{Results}

\section{Descriptive Statistics}

Descriptive data and bivariate correlations are presented in Table 1. In addition, means and standard deviations for avoidance, revenge, benevolence, forgiveness of self, forgiveness of others, and forgiveness of uncontrollable situations with respect to participants who have experienced IPV and those who have not experienced IPV are reported in Table 2. To examine potential differences between the means for each group, independent samples $t$ tests were analyzed; all $t$ tests were significant with the exception of the mean difference on revenge.

\section{Hypotheses Testing}

Eight simultaneous multivariate regression models were estimated via path modeling using maximum likelihood estimation within Mplus Version 6.0 (Muthen \& Muthen, 1998-2010). One model simultaneously examined 
Table 2. Means and Standard Deviations for Outcome Measures Comparing IPV Survivors and Non-IPV Survivors.

\begin{tabular}{lrc}
\hline Variable & IPV Survivor $(n=365)$ & Non-IPV Survivor $(n=135)$ \\
\hline 1. Avoidance $^{\star *}$ & $22.24(8.34)$ & $19.55(8.55)$ \\
2. Revenge & $8.64(3.91)$ & $7.93(3.23)$ \\
3. Benevolence** & $18.58(6.07)$ & $20.46(5.87)$ \\
4. Forgiveness of self** & $28.73(5.85)$ & $30.39(6.22)$ \\
5. Forgiveness of others & $29.50(6.75)$ & $31.45(6.48)$ \\
6. Forgiveness of situations* $^{*}$ & $29.33(5.95)$ & $30.89(6.18)$ \\
\hline
\end{tabular}

IPV = intimate partner violence.

${ }^{*} p<.05 .{ }^{* *} p<.01$ for $t$ test comparison of means.

the experience of IPV dichotomously as associated with avoidance, revenge, and benevolence, whereas the second model simultaneously examined the experience of IPV dichotomously as associated with forgiveness of self, forgiveness of others, and forgiveness of uncontrollable situations. The third and fourth models simultaneously examined the frequency of IPV experiences as associated with avoidance, revenge, and benevolence, and the frequency of IPV experiences as associated with forgiveness of self, forgiveness of others, and forgiveness of uncontrollable situations, respectively. Regarding the examination of types of IPV, the fifth and sixth models simultaneously examined the experience of psychological IPV and physical IPV dichotomously as associated with avoidance, revenge, and benevolence, and the experience of psychological IPV and physical IPV dichotomously as associated with forgiveness of self, forgiveness of others, and forgiveness of uncontrollable situations, respectively. Finally, the last two models simultaneously examined the frequency of psychological IPV experiences and physical IPV experiences as associated with avoidance, revenge, and benevolence, and the frequency of psychological IPV experiences and physical IPV experiences as associated with forgiveness of self, forgiveness of others, and forgiveness of uncontrollable situations, respectively. The regression models were estimated with 10,000 bootstrap samples as recommended in current research to reduce potential sampling errors (Fox, 2008) and provide confidence intervals that are believed to be more informative than traditional significance testing alone (American Psychological Association, 2009; Cumming \& Finch, 2005). The bootstrapped unstandardized coefficients and errors, as well as $95 \%$ bias-corrected confidence intervals, are reported in Table 3 (Williams \& MacKinnon, 2008). If the 95\% confidence interval does not contain zero, then the effects are considered significant (see Mallinckrodt, Abraham, Wei, \& Russell, 2006). 
Table 3. Bootstrap Analysis of Multivariate Regression Examining Total IPV Dichotomously.

\begin{tabular}{|c|c|c|c|c|c|c|}
\hline \multirow[b]{2}{*}{ Hypothesis } & \multirow[b]{2}{*}{ Predictor } & \multirow[b]{2}{*}{ Criterion } & \multirow[b]{2}{*}{$B$} & \multirow[b]{2}{*}{$S E$} & \multicolumn{2}{|c|}{ 95\% Confidence } \\
\hline & & & & & $\begin{array}{l}\text { Lower } \\
\text { Bound }\end{array}$ & $\begin{array}{l}\text { Upper } \\
\text { Bound }\end{array}$ \\
\hline $1 a$ & IPV & Avoidance & 2.69 & $.86^{* \star}$ & 1.01 & 4.38 \\
\hline $1 b$ & IPV & Revenge & 0.71 & $.34^{\star}$ & 0.04 & 1.39 \\
\hline $1 c$ & IPV & Benevolence & -1.88 & $.60^{* \star}$ & -3.05 & -0.71 \\
\hline $2 a$ & IPV & Self & -1.67 & $.62^{* *}$ & -2.88 & -0.45 \\
\hline $2 b$ & IPV & Others & -1.95 & $.67^{\star \star}$ & -3.26 & -0.64 \\
\hline $2 c$ & IPV & Situations & -1.56 & $.63^{*}$ & -2.79 & -0.33 \\
\hline
\end{tabular}

IPV denotes total intimate partner violence scores examined dichotomously. Self denotes forgiveness of self. Others denotes forgiveness of others. Situations denotes forgiveness of uncontrollable situations. If the $95 \%$ confidence interval does not contain zero, then the effects are considered significant (see Mallinckrodt, Abraham, Wei, \& Russell, 2006). IPV = intimate partner violence.

${ }^{*} p<.05 .{ }^{* *} p<.01$.

Importantly, fully saturated models, such as those tested in the present study, yield perfect fit by definition because all possible paths are estimated. First, we assessed the hypotheses regarding simply the experience of IPV (or not) as associated with various components of both transgression-specific and dispositional forgiveness as measured by the TRIM-18R and the HFS. As Table 3 shows, a positive relation emerged between IPV and both avoidance and revenge, whereas negative associations emerged between IPV and (a) benevolence, (b) forgiveness of self, (c) forgiveness of others, and (d) forgiveness of uncontrollable situations; these findings are consistent with all aspects of Hypotheses 1 and 2. The proportions of variance explained in the models were $R 2=.020$ for avoidance, $R 2=.007$ for revenge, $R 2=.019$ for benevolence, $R 2=.015$ for forgiveness of self, $R 2=$ .017 for forgiveness of others, and $R 2=.013$ for forgiveness of situations.

Second, we assessed the hypotheses regarding the frequency of experiencing IPV as associated with components of transgression-specific and dispositional- related forgiveness. As Table 4 shows, the same pattern of relations, with the exception of revenge, that emerged when examining these associations based on the dichotomous measure of IPV was revealed for frequency of IPV. Higher frequencies of IPV were positively associated with avoidance, and were negatively associated with (a) benevolence, (b) forgiveness of self, (c) forgiveness of others, and (d) forgiveness of uncontrollable situations. These results are consistent with Hypotheses 3a, 3c, 4a, 4b, and 
Table 4. Bootstrap Analysis of Multivariate Regression Examining Total Frequency of IPV.

\begin{tabular}{|c|c|c|c|c|c|c|}
\hline \multirow[b]{2}{*}{ Hypothesis } & \multirow[b]{2}{*}{ Predictor } & \multirow[b]{2}{*}{ Criterion } & \multirow[b]{2}{*}{$B$} & \multirow[b]{2}{*}{$S E$} & \multicolumn{2}{|c|}{ 95\% Confidence } \\
\hline & & & & & $\begin{array}{l}\text { Lower } \\
\text { Bound }\end{array}$ & $\begin{array}{l}\text { Upper } \\
\text { Bound }\end{array}$ \\
\hline $3 a$ & IPV & Avoidance & .25 & $.08^{\star \star}$ & .10 & .39 \\
\hline $3 b$ & IPV & Revenge & .08 & .04 & -.00 & .17 \\
\hline $3 c$ & IPV & Benevolence & -.25 & $.06^{\star \star *}$ & -.35 & -.14 \\
\hline $4 a$ & IPV & Self & -.20 & $.06^{\star *}$ & -.32 & -.08 \\
\hline $4 b$ & IPV & Others & -.16 & $.07^{*}$ & -.29 & -.02 \\
\hline $4 c$ & IPV & Situations & -.21 & $.05^{\star \star \star}$ & -.31 & -.10 \\
\hline
\end{tabular}

IPV denotes the total frequency of intimate partner violence scores. Self denotes forgiveness of self. Others denotes forgiveness of others. Situations denotes forgiveness of uncontrollable situations. If the $95 \%$ confidence interval does not contain zero, then the effects are considered significant (see Mallinckrodt, Abraham, Wei, \& Russell, 2006). IPV = intimate partner violence.

${ }^{*} p<.05 .{ }^{* *} p<.01$. ${ }^{* *} p<.001$.

4c. The association between the frequency of IPV and revenge was not significant, which is inconsistent with Hypothesis $3 \mathrm{~b}$, although it was in the hypothesized direction. The proportions of variance explained in the models were $R 2=.022$ for avoidance, $R 2=.012$ for revenge, $R 2=.042$ for benevolence, $R 2=.029$ for forgiveness of self, $R 2=.014$ for forgiveness of others, and $R 2=.031$ for forgiveness of situations.

Next, we assessed the hypotheses regarding simply the experience of psychological IPV (or not) and physical IPV (or not) as associated with various components of both transgression-specific and dispositional forgiveness. As shown in Table 5, positive relations emerged between the experience of psychological IPV and avoidance, and the experience of physical IPV and revenge. Additionally, the experience of physical IPV (or not) was negatively associated with benevolence. Furthermore, the experience of psychological IPV (or not) was positively associated with both forgiveness of others and forgiveness of uncontrollable situations. These findings are partially consistent with Hypotheses 5a, 5b, 5c, 6b, and 6c. However, inconsistent with Hypothesis 6a, no significant associations emerged regarding the experience of psychological IPV and forgiveness of self. Forgiveness of self also was not related to the experience of physical IPV. The proportions of variance explained in the models were $R 2=.027$ for avoidance, $R 2=.023$ for revenge, $R 2=.036$ for benevolence, $R 2=.021$ for forgiveness of self, $R 2$ $=.020$ for forgiveness of others, and $R 2=.015$ for forgiveness of situations. 
Table 5. Bootstrap Analysis of Multivariate Regression Examining Types of IPV Dichotomously.

\begin{tabular}{|c|c|c|c|c|c|c|}
\hline \multirow[b]{2}{*}{ Hypothesis } & \multirow[b]{2}{*}{ Predictor } & \multirow[b]{2}{*}{ Criterion } & \multirow[b]{2}{*}{$B$} & \multirow[b]{2}{*}{$S E$} & \multicolumn{2}{|c|}{ 95\% Confidence } \\
\hline & & & & & $\begin{array}{l}\text { Lower } \\
\text { Bound }\end{array}$ & $\begin{array}{l}\text { Upper } \\
\text { Bound }\end{array}$ \\
\hline $5 a$ & IPV physical & Avoidance & 1.53 & .86 & -0.14 & 3.21 \\
\hline $5 a$ & IPV psychological & Avoidance & 1.97 & $.96^{\star}$ & 0.08 & 3.85 \\
\hline $5 b$ & IPV physical & Revenge & 1.15 & $.41^{* *}$ & 0.35 & 1.94 \\
\hline $5 b$ & IPV psychological & Revenge & 0.019 & .41 & -0.78 & 0.82 \\
\hline $5 c$ & IPV physical & Benevolence & -1.64 & $.63^{* *}$ & -2.88 & -0.40 \\
\hline $5 c$ & IPV psychological & Benevolence & -1.20 & .69 & -2.56 & 0.15 \\
\hline $6 a$ & IPV physical & Self & -1.09 & .59 & -2.23 & 0.07 \\
\hline $6 a$ & IPV psychological & Self & -1.08 & .65 & -2.36 & 0.20 \\
\hline $6 b$ & IPV physical & Others & -0.23 & .68 & -1.56 & 1.10 \\
\hline $6 b$ & IPV psychological & Others & -1.99 & $.73^{* *}$ & -3.42 & -0.56 \\
\hline $6 c$ & IPV physical & Situations & -0.29 & .60 & -1.46 & 0.88 \\
\hline $6 c$ & IPV psychological & Situations & -1.48 & $.67^{\star}$ & -2.80 & -0.16 \\
\hline
\end{tabular}

IPV denotes types of intimate partner violence scores examined dichotomously. Self denotes forgiveness of self. Others denotes forgiveness of others. Situations denotes forgiveness of uncontrollable situations. If the $95 \%$ confidence interval does not contain zero, then the effects are considered significant (see Mallinckrodt, Abraham, Wei, \& Russell, 2006). IPV = intimate partner violence.

${ }^{*} p<.05 .{ }^{* *} p<.01$.

Finally, we assessed the hypotheses regarding the frequency of experiencing psychological IPV and physical IPV as associated with aspects of transgression- specific and dispositional forgiveness. As Table 6 depicts, partially consistent with Hypothesis 7a, a positive relation emerged between the frequency of experiencing psychological IPV and avoidance. In addition, partially consistent with Hypothesis 8a, a negative relation emerged between the frequency of experiencing psychological IPV and forgiveness of self. However, inconsistent with the remaining hypotheses, no significant associations emerged between the frequency of psychological IPV and revenge, benevolence, forgiveness of others, and forgiveness of uncontrollable situations. The frequency of physical IPV was not associated with any of the outcome variables. The proportions of variance explained in the models were $R 2=.027$ for avoidance, $R 2=.016$ for revenge, $R 2=.046$ for benevolence, $R 2=.030$ for forgiveness of self, $R 2=.015$ for forgiveness of others, and $R 2=.031$ for forgiveness of situations. 
Table 6. Bootstrap Analysis of Multivariate Regression Examining Frequency of IPV Types.

\begin{tabular}{|c|c|c|c|c|c|c|}
\hline \multirow[b]{2}{*}{ Hypothesis } & \multirow[b]{2}{*}{ Predictor } & \multirow[b]{2}{*}{ Criterion } & \multirow[b]{2}{*}{$B$} & \multirow[b]{2}{*}{$S E$} & \multicolumn{2}{|c|}{ 95\% Confidence } \\
\hline & & & & & $\begin{array}{l}\text { Lower } \\
\text { Bound }\end{array}$ & $\begin{array}{l}\text { Upper } \\
\text { Bound }\end{array}$ \\
\hline $7 a$ & IPV physical & Avoidance & -.16 & .38 & -.90 & .58 \\
\hline $7 a$ & IPV psychological & Avoidance & .43 & $.15^{\star \star}$ & .12 & .73 \\
\hline $7 b$ & IPV physical & Revenge & .27 & .20 & -.12 & .65 \\
\hline $7 b$ & IPV psychological & Revenge & .01 & .06 & -.12 & .14 \\
\hline $7 c$ & IPV physical & Benevolence & -.39 & .27 & -.92 & .14 \\
\hline $7 c$ & IPV psychological & Benevolence & -.20 & .11 & -.42 & .01 \\
\hline $8 a$ & IPV physical & Self & -.15 & .26 & -.67 & .36 \\
\hline $8 a$ & IPV psychological & Self & -.22 & $.11^{\star}$ & -.44 & -.01 \\
\hline $8 b$ & IPV physical & Others & -.18 & .36 & -.88 & .52 \\
\hline $8 b$ & IPV psychological & Others & -.15 & .13 & -.41 & .11 \\
\hline $8 c$ & IPV physical & Situations & -.22 & .25 & -.71 & .27 \\
\hline $8 c$ & IPV psychological & Situations & -.21 & .11 & -.43 & .01 \\
\hline
\end{tabular}

IPV denotes the frequency of types of intimate partner violence scores. Self denotes forgiveness of self. Others denotes forgiveness of others. Situations denotes forgiveness of uncontrollable situations. If the $95 \%$ confidence interval does not contain zero, then the effects are considered significant (see Mallinckrodt, Abraham, Wei, \& Russell, 2006). IPV = intimate partner violence.

${ }^{*} p<.05 .{ }^{* *} p<.01$.

\section{Discussion}

These results provide compelling information regarding forgiveness and IPV among college women. To our knowledge, this is the first research to examine relations between IPV and attitudes toward transgression-specific and dispositional forgiveness.

Generally speaking and consistent with the hypotheses, the overall experience of IPV, whether examined dichotomously with respect to simply having the IPV experience or not, or continuously with respect to frequency of the IPV experiences, was significantly associated with both transgression-specific and dispositional forgiveness. More specifically, results from both dichotomous and continuous measures of IPV indicated a positive association between the experience of IPV and avoidance, as well as negative associations between IPV and (a) benevolence, (b) forgiveness of self, (c) forgiveness of others, and (d) forgiveness of uncontrollable situations. However, partially consistent with hypotheses, a significant association was demonstrated between dichotomously measured IPV and 
revenge, whereas this relation did not emerge with respect to frequency of IPV. The findings that women's experiences of IPV are associated with both transgression-specific and dispositional forgiveness may speak to the overall and specific impact that IPV has on survivors. The experience of IPV may negatively affect survivors' overall view of people and trust, thereby influencing their general disposition toward forgiveness, in addition to their more directed forgiveness toward someone who has specifically transgressed upon them. Given that very nearly the same pattern of results emerged when examining the experience of IPV from both dichotomous and continuous perspectives, and because one more association was found when examined dichotomously, it appears that the mere experience of IPV may be a meaningful enough event, in and of itself, to influence a woman's motivations toward forgiveness, and that the frequency of IPV is not a salient condition. The psychological trauma incurred as a result of experiencing violence from an intimate partner, regardless of frequency, may explain these findings.

\section{Types of IPV and Forgiveness}

To better understand the ways in which the experience of IPV may be related to forgiveness, the overall experience of IPV was divided into psychological IPV and physical IPV, and was examined in relation to transgression-specific and dispositional forgiveness. With regard to the dichotomous analyses and these two types of IPV, findings indicated a positive association between the experience of psychological IPV and avoidance, whereas negative associations emerged between psychological IPV and forgiveness of both others and uncontrollable situations. These results suggest that women who have experienced psychological IPV may demonstrate a propensity to avoid transgressors, as well as may exhibit less forgiveness of others and less forgiveness of uncontrollable situations than women who have not experienced psychological IPV.

This avoidance may be related to coping and interpersonal styles (Horney, 1970). More specifically, an interpersonal style of "moving away" is characterized by physical avoidance and emotional withdrawal (Teyber \& McClure, 2011). According to Endler and Parker (2000), avoidance-oriented coping attempts to reduce stress through activities or cognitive changes that avoid confrontation with people or situations. Thus, this type of avoidant interpersonal style may have developed and served as a coping mechanism for women who have experienced this type of abuse from a partner. Although this type of coping has benefits (e.g., less contact with the transgressor and/ or the transgression, safe spaces free of confrontation and potential further abuse), this behavior can be problematic in the long term, 
particularly if it generalizes to other significant relationships in the survivor's life (e.g., family, friends, future partners); avoidance-oriented coping has been shown to be maladaptive over time and is associated with negative psychological and physiological outcomes (Barlow, 2001; Blalock \& Joiner, 2000; Carver, Scheier, \& Weintraub, 1989; Craske, 2003; Holahan \& Moos, 1986; Mullen \& Suis, 1982; Suls \& Fletcher, 1985). Importantly, Strelan and Wojtysiak (2009) found that such avoidance is an adaptive initial coping strategy that may provide the foundation for higher level and healthier approach-oriented coping that includes more direct responses and taking actions to deal with the transgression.

Previous research aids in interpreting the negative association between women who have experienced psychological IPV and forgiveness of others and of uncontrollable situations. Specifically, these findings are consistent with prior research demonstrating that individuals with a history of IPV have an increased inability to trust others compared with those with no history of experiencing IPV (Clements et al., 2004; Felitti et al., 1998; Golding et al., 2002; Yuan et al., 2006). The difficulty with trust in others could be detrimental to creating a strong social support system, which is important within the healing process of IPV (Beeble, Bybee, Sullivan, \& Adams, 2009; Bybee \& Sullivan, 2002; Mertin \& Mohr, 2001; C. M. Sullivan \& Bybee, 1999; Tan, Basta, Sullivan, \& Davidson, 1995). In regard to a negative association with forgiveness of uncontrollable situations, control may be the salient factor. Because IPV is an experience that robs victims of control (Dutton \& Goodman, 2005; Johnson, 1995; Pence \& Paymar, 1993; Stark, 2007), the negative association between psychological IPV experiences and forgiveness of uncontrollable situations is logical. Perhaps, when control remains outside of victims' power, they are not prone to forgiveness when faced with situations that are uncontrollable. Furthermore, perceptions of control over one's life, and thus self-sufficiency, are associated with improved adjustment following the experience of trauma (Frazier et al., 2011). Thus, women with psychological IPV experiences may require a sense of control over situations to move forward positively in their lives. This strong need for control may in turn explain the dispositional tendency displayed in the negative association with forgiveness of uncontrollable situations.

With respect to physical IPV, the dichotomous analyses indicated that the experience of physical IPV was related to the transgression-specific forgiveness aspects of revenge and benevolence. More specifically, a significant positive association emerged between the experience of physical IPV and revenge, whereas a significant negative association emerged between physical IPV and benevolence. These findings fit well with Hor- 
ney's (1970) characterization of "moving against" others as a coping and interpersonal style. According to Teyber and McClure (2011), "moving against" is defined as approaching relationships in an aggressive manner, accompanied by attempts to control others. This type of interpersonal style may serve as a coping mechanism for women who have experienced physical IPV, and may have developed as a result of experiencing this type of partner abuse. In addition, this more aggressive interpersonal style aligns with the notion of victims wanting to "get back at" their abusers. Although participants with experiences of physical IPV may have responded to the TRIM-18R with respect to their abuser, this finding shows that women who have experienced physical IPV may exhibit a propensity for retaliation motivation toward transgressors more generally. These feelings of revenge are akin to holding a grudge, which has been shown to be somewhat beneficial for people as it may provide a sense of control (Baumeister, Exline, \& Sommer, 1998). Given the ways in which IPV incurs a loss of power and control for victims (Dutton \& Goodman, 2005; Stark, 2007), this potential reassertion of control through vengeful motivations is understandable. Relatedly, a negative association with benevolence indicates an inability to move past the hurt that the transgressor caused and develop more positive relations with the transgressor. This finding is reasonable in light of the revenge findings. If women are seeking revenge from transgressors, they may have difficulty reestablishing compassion and kindness toward these transgressors. This is consistent with previous research that has demonstrated associations between the experience of IPV and an inability to trust others (Clements et al., 2004; Felitti et al., 1998; Golding et al., 2002; Yuan et al., 2006).

With regard to the continuous analyses and the frequency of psychological IPV and physical IPV in regard to forgiveness, findings indicated only two significant associations. A positive association emerged between the frequency of psychological IPV and avoidance, as well as a negative association between the frequency of psychological IPV and forgiveness of self. The negative relation between the frequency of experiencing psychological IPV and forgiveness of self may be explained by potential shame (Rhatigan et al., 2011; Spangaro et al., 2011) and self-blame or self-attribution that survivors experience (Katz et al., 1997). The lack of significant associations for the other analyses is contrary to our hypotheses. One interpretation for these results is that the mere experience of psychological IPV and/or physical IPV is an important enough event in and of itself to influence a woman's motivations toward transgression-specific and dispositional forgiveness, and that the frequency of these abuses is not the salient factor. 


\section{Limitations and Future Research}

Despite the important and novel findings revealed by this study, it is not without limitations. First, the use of self-report measures raises some concern regarding potential response bias and image management by participants. Second, the primarily White sample in this research limits the generalizability of the current findings to more culturally diverse populations. Similarly, given that the participant sample consists of college students, the ability to generalize the findings to non-college women is restricted. Finally, due to the correlational nature of this study, the causal links between variables should be interpreted with caution. For example, it is possible that having a less forgiving disposition predicts more IPV or a third variable (e.g., religiosity) predicts both IPV and forgiveness.

The present study creates numerous ideas for future research, as little has been done to date with regard to IPV and forgiveness. For example, given differential associations found between experiences of physical IPV and psychological IPV with a variety of forgiveness outcomes, future research could more directly compare physical IPV and psychological IPV experiences. In addition, given the amount of variance accounted for in the analyses was low, future research could examine a number of other constructs not explored in the current study to help explain this unaccounted variability. These constructs include, but are not limited to, the length of the intimate relationship between victim and perpetrator, as well as religiosity. Competing hypotheses explaining the relations demonstrated here also should be studied, including the possibility that being less forgiving is a trait among women who are in abusive intimate partner relationships. Relatedly, because dispositional forgiveness may be a trait that develops with age and experience, future research examining age specifically or using a developmental or longitudinal approach may prove useful to fully understanding the associations between IPV and forgiveness.

Regarding forgiveness of self, others, and uncontrollable situations, additional research could explore how the lack of forgiveness could affect helpseeking, utilization of support, and perceptions of control. In addition, therapeutic work with IPV survivors may be informed by investigations that explore clinical outcomes that result from focusing on forgiveness of self, others, and uncontrollable situations in therapy. Furthermore, future research could examine the utility of forgiveness with respect to resilience and recovery from abusive intimate partner relationships. Whereas previous literature asserts the usefulness and benefits of forgiveness (Brown, 2003; McCullough et al., 1998; Thompson et al., 2005), it may be that forgiveness is not as useful a construct in the context of an abusive relationship. Finally, studies should seek more racially diverse and non-collegiate samples. 


\section{Conclusion}

This investigation examined IPV and forgiveness among college women. More specifically, overall experiences of IPV as well as experiences of psychological and physical IPV were investigated with respect to transgression specific forgiveness, including avoidance, revenge, and benevolence, and dispositional forgiveness, including forgiveness of self, others, and uncontrollable situations. The current research begins to fill critical gaps in the current literature, as this is one of the first studies to examine IPV and a general forgiveness orientation (e.g., including of the abuser, but also of self, other people, and situations). In sum, this research suggests that (a) the experience of IPV is associated with higher levels of avoidance and revenge, and lower levels of benevolence, forgiveness of self, forgiveness of others, and forgiveness of uncontrollable situations; (b) types of IPV demonstrate differing impacts on forgiveness; and (c) the mere experience of such partner abuse is more salient than its frequency.

Conflicting Interests - The authors declared no potential conflicts of interest with respect to the research, authorship, and/or publication of this article.

Funding - The authors received no financial support for the research, authorship, and/or publication of this article.

\section{References}

American Psychological Association. (2009). Publication manual of the American Psychological Association (6th ed.). Washington, DC: Author. Barlow, D. H. (2001). Anxiety and its disorders (2nd ed.). New York, NY: Guilford Press.

Baumeister, R. F., Exline, J. J., \& Sommer, K. L. (1998). The victim role, grudge theory, and two dimensions of forgiveness. In E. L. Worthington Jr. (Ed.), Dimensions of forgiveness (pp. 79-104). Philadelphia, PA: Templeton Foundation Press.

Becker, K. D., Stuewig, J., \& McCloskey, L. A. (2010). Traumatic stress symptoms of women exposed to different forms of childhood victimization and intimate partner violence. Journal of Interpersonal Violence, 25, 1699-1715. doi 10.1177/0886260509354578

Beeble, M. L., Bybee, D., Sullivan, C. M., \& Adams, A. E. (2009). Main, mediating, and moderating effects of social support on the well-being of survivors of intimate partner violence across 2 years. Journal of Consulting and Clinical Psychology, 77, 718-729. doi 10.1037/a0016140

Black, M. C., Basile, K. C., Breiding, M. J., Smith, S. G., Walters, M. L., Merrick, M. T., ... Stevens, M. R. (2011). The National Intimate Partner and Sexual Violence Survey (NISVS): 2010 summary report. Atlanta, GA: National Center for 
Injury Prevention and Control, Centers for Disease Control and Prevention.

Blalock, J. A., \& Joiner, T. E., Jr. (2000). Interaction of cognitive avoidance coping and stress in predicting depression/anxiety. Cognitive Therapy and Research, 24, 47-65. doi 10.1023/A:1005450908245

Brown, R. P. (2003). Measuring individual differences in the tendency to forgive: Construct validity and links with depression. Personality and Social Psychology Bulletin, 29, 759-771. doi 10.1177/0146167203029006008

Burch, R. L., \& Gallup, G. G. (2000). Perceptions of paternal resemblance predict family violence. Evolution \& Human Behavior, 21, 429-435. doi 10.1016/ S1090- 5138(00)00056-8

Bybee, D., \& Sullivan, C. M. (2002). The process through which an advocacy intervention resulted in positive change for battered women over time. American Journal of Community Psychology, 30, 103-132. doi 10.1023/A:1014376202459

Carver, C. S., Scheier, M. F., \& Weintraub, J. K. (1989). Assessing coping strategies: A theoretically based approach. Journal of Personality and Social Psychology, 56, 267-283. doi 10.1037//0022-3514.56.2.267 Centers for Disease Control and Prevention, National Center for Injury Prevention and Control. (2008). Intimate partner violence: Definitions. http:// www.cdc.gov/ViolencePrevention/intimatepartnerviolence/definitions.html

Centers for Disease Control and Prevention, National Center for Injury Prevention and Control. (2010). Injury prevention and control: Violence prevention. http://www.cdc.gov/violenceprevention/intimatepartnerviolence/definitions. html Cerney, M. S. (1988). "If only ... " Remorse in grief therapy. Psychotherapy Patient, 5, 235-248. doi 10.1300/J358v05n01_18

Clements, P. T., Speck, P. M., Crane, P. A., \& Faulkner, M. J. (2004). Issues and dynamics of sexually assaulted adolescents and their families. International Journal of Mental Health Nursing, 13, 267-274. doi 10.1111/j.1445-8330.2004.00344.x

Coker, A. L., Smith, P. H., McKeown, R. E., \& King, M. J. (2000). Frequency and correlates of intimate partner violence by type: Physical, sexual, and psychological battering. American Journal of Public Health, 90, 553-559. doi 10.2105/AJPH.90.4.553

Coop Gordon, K., Burton, S., \& Porter, L. (2004). Predicting the intentions of women in domestic violence shelters to return to partners: Does forgiveness play a role? Journal of Family Psychology, 18, 331-338. doi 10.1037/0893-3200.18.2.331

Cosgrove, L., \& Konstam, V. (2008). Forgiveness and forgetting: Clinical implications for mental health counselors. Journal of Mental Health Counseling, 30, 1-13.

Craske, M. (2003). Origins of phobias and anxiety disorders: Why more women than men? Kidlington, UK: Elsevier.

Cumming, G., \& Finch, S. (2005). Inference by eye: Confidence intervals, and how to read pictures of data. American Psychologist, 60, 170-180. doi 10.1037/0003-066X.60.2.170 
Dutton, M. A., \& Goodman, L. A. (2005). Coercion in intimate partner violence: Toward a new conceptualization. Sex Roles, 52, 743-756. doi 10.1007/ s11199- 005-4196-6

Endler, N. S., \& Parker, J. D. A. (2000). Coping with health injuries and problems (CHIP). New York, NY: Multi-Health Systems.

Enright, R. D., Eastin, D. L., Golden, S., Sarinopoulos, I., \& Freedman, S. (1992). Interpersonal forgiveness within the helping professions: An attempt to resolve differences of opinion. Counseling and Values, 36, 84-103. doi 10.1002/ j.2161- 007X.1991.tb00966.x

Enright, R. D., \& Fitzgibbons, R. P. (2000). Helping clients forgive: An empirical guide for resolving anger and restoring hope. Washington, DC: American Psychological Association. doi 10.1037/10381-000

Falsetti, S. A., Resick, P. A., \& Davis, J. L. (2003). Changes in religious beliefs following trauma. Journal of Traumatic Stress, 16, 391-398. doi 10.1023/A:1024422220163

Fass, D. F., Benson, R. I., \& Leggett, D. G. (2008). Assessing prevalence and awareness of violent behaviors in the intimate partner relationships of college students using internet sampling. Journal of College Student Psychotherapy, 22, 66-75. doi 10.1080/87568220801952248

Felitti, V. J., Anda, R. F., Nordenberg, D., Williamson, D. F., Spitz, A. M., Edwards, V., . . Marks, J. S. (1998). Relationship of childhood abuse and household dysfunction to many of the leading causes of death in adults: The Adverse Childhood Experiences Study. American Journal of Preventive Medicine, 14, 245-258. doi 10.1016/S0749-3797(98)00017-8

Fitzgibbons, R. P. (1986). The cognitive and emotive uses of forgiveness in the treatment of anger. Psychotherapy, 23, 629-633. doi 10.1037/h0085667

Fox, J. (2008). Applied regression analysis and generalized linear models (2nd ed.). Thousand Oaks, CA: Sage.

Frazier, P., Keenan, N., Anders, S., Perera, S., Shallcross, S., \& Hintz, S. (2011). Perceived past, present, and future control and adjustment to stressful life events. Journal of Personality and Social Psychology, 100, 749-765. doi $10.1037 / \mathrm{a} 0022405$

Fredrickson, B. L. (1998). What good are positive emotions? Review of General Psychology, 2, 300-319. doi 10.1037/1089-2680.2.3.300

Fredrickson, B. L. (2001). The role of positive emotions in positive psychology: The broaden and-build theory of positive emotions. American Psychologist, 56, 218-226. doi 10.1037/0003-066X.56.3.218

Fredrickson, B. L. (2003). The value of positive emotions. American Scientist, 91, 330-335. doi 10.1511/2003.4.330

Fredrickson, B. L., Mancuso, R. A., Branigan, C., \& Tugade, M. M. (2000). The undoing effect of positive emotions. Motivation and Emotion, 24, 237-258. doi 10.1023/A:1010796329158

Freedman, S. R. (1998). Forgiveness and reconciliation: The importance of understanding how they differ. Counseling and Values, 42, 200-216. doi 10.1002/j.2161-007X.1998.tb00426.x 
Gervais, S. J., \& Davidson, M. M. (2013). Objectification among college women in the context of intimate partner violence. Violence and Victims, 28, 36-49. doi 10.1891/0886-6708.28.1.36

Golding, J. M., Wilsnack, S. C., \& Cooper, M. L. (2002). Sexual assault history and social support: Six general population studies. Journal of Traumatic Stress, 15, 187-197. doi 10.1023/A:1015247110020

Holahan, C. J., \& Moos, R. H. (1986). Personality, coping and family resources in stress resistance: A longitudinal analysis. Journal of Personality and Social Psychology, 51, 389-395. doi 10.1037//0022 3514.51.2.389

Horney, K. (1970). Neuroses and human growth. New York, NY: Norton.

Johnson, M. P. (1995). Patriarchal terrorism and common couple violence: Two forms of violence against women. Journal of Marriage and the Family, 57, 283-295. doi 10.2307/353683

Katz, J., Street, A., \& Arias, I. (1997). Individual differences in self-appraisal and responses to dating violence scenarios. Violence and Victims, 12, 265-276.

Linley, P. A., \& Joseph, S. (2004). Positive change following trauma and adversity: A review. Journal of Traumatic Stress, 17, 11-21. doi 10.1023/ B:JOTS.0000014671.27856.7e

Magyar-Moe, J. L. (2009). Therapist's guide to positive psychological interventions. Burlington, MA: Academic Press.

Mallinckrodt, B., Abraham, W., Wei, M., \& Russell, D. W. (2006). Advances in testing the statistical significance of mediation effects. Journal of Counseling Psychology, 53, 372-378. doi 10.1037/0022-0167.53.3.372

McCullough, M. E. (2000). Forgiveness as human strength: Theory, measurement, and links to well-being. Journal of Social \& Clinical Psychology, 19, 4355. doi 10.1521/jscp.2000.19.1.43

McCullough, M. E., \& Hoyt, W. T. (2002). Transgression-related motivational dispositions: Personality substrates of forgiveness and their links to the big five. Personality and Social Psychology Bulletin, 28, 1556-1573. doi 10.1177/014616702237583

McCullough, M. E., Rachal, K. C., Sandage, S. J., Worthington, E. L., Brown, S. W., \& Hight, T. L. (1998). Interpersonal forgiving in close relationships: II. Theoretical elaboration and measurement. Journal of Personality and Social Psychology, 75, 1586-1603. doi 10.1037//0022-3514.75.6.1586

McCullough, M. E., Root, L. M., Tabak, B., \& Witvliet, C. V. O. (2009). Forgiveness. In S. J. Lopez (Ed.), Handbook of positive psychology (2nd ed., pp. 427435). New York, NY: Oxford University Press.

McNulty, J. K. (2011). The dark side of forgiveness: The tendency to forgive predicts continued psychological and physical aggression in marriage. Personality and Social Psychology Bulletin, 37, 770-783.

Mechanic, M. B., Weaver, T. L., \& Resick, P. A. (2008). Mental health consequences of intimate partner abuse: A multidimensional assessment of four different forms of abuse. Violence Against Women, 14, 634-654. doi 10.1177/1077801208319283

Mertin, P., \& Mohr, P. B. (2001). A follow-up study of posttraumatic stress disor- 
der, anxiety, and depression in Australian victims of domestic violence. $\mathrm{Vi}$ olence and Victims, 16, 645-654.

Mills, R. B., \& Malley-Morrison, K. (1998). Emotional commitment, normative acceptability, and attributions for abusive partner behaviors. Journal of Interpersonal Violence, 13, 682-699. doi 10.1177/088626098013006002

Mullen, B., \& Suis, J. (1982). The effectiveness of attention and rejection as coping styles: A meta-analysis of temporal differences. Journal of Psychosomatic Research, 26, 43-49. doi 10.1016/0022-3999(82)90061-7

Muthen, L. K., \& Muthen, B. O. (1998-2010). Mplus user's guide. Los Angeles, CA: Author. Neufeld, J., McNamara, J. R., \& Ertl, M. (1999). Incidence and prevalence of dating partner abuse and its relationship to dating practices. Journal of Interpersonal Violence, 14, 125-137. doi 10.1177/088626099014002002

Pence, E., \& Paymar, M. (1993). Education groups for men who batter: The Duluth model. New York, NY: Springer.

Pico-Alfonso, M. A., Garcia-Linares, M. I., Celda-Navarro, N., Blasco-Ros, C., Echeburua, E., \& Martinez, M. (2006). The impact of physical, psychological, and sexual intimate male partner violence on women's mental health: Depressive symptoms, posttraumatic stress disorder, state anxiety, and suicide. Journal of Women's Health, 15, 599-611. doi 10.1089/jwh.2006.15.599

Rhatigan, D. L., Shorey, R. C., \& Nathanson, A. M. (2011). The impact of posttraumatic symptoms on women's commitment to a hypothetical violent relationship: A path analytic test of posttraumatic stress, depression, shame, and self-efficacy on investment model factors. Psychological Trauma: Theory, Research, Practice, and Policy, 3, 181-191. doi 10.1037/a0020646

Seligman, M. E. P., \& Csikszentmihalyi, M. (2000). Positive psychology: An introduction. American Psychologist, 55, 51-82. doi 10.1037//0003-066X.55.1.5

Shepard, M. F., \& Campbell, J. A. (1992). The Abusive Behavior Inventory: A measure of psychological and physical abuse. Journal of Interpersonal Violence, 7, 291-305. doi 10.1177/088626092007003001

Spangaro, J. M., Zwi, A. B., \& Poulos, R. G. (2011). "Persist. persist.”: A qualitative study of women's decisions to disclose and their perceptions of the impact of routine screening for intimate partner violence. Psychology of Violence, 1, 150-162. doi 10.1037/a0023136

Stark, E. (2007). Coercive control: How men entrap women in personal life. New York, NY: Oxford University Press.

Strelan, P., \& Wojtysiak, N. (2009). Strategies for coping with interpersonal hurt: Preliminary evidence for the relationship between coping and forgiveness. Counseling and Values, 53, 97-111. doi 10.1002/j.2161-007X.2009.tb0 0117.x

Sullivan, C. M., \& Bybee, D. I. (1999). Reducing violence using community-based advocacy for women with abusive partners. Journal of Consulting and Clinical Psychology, 67, 43-53. doi 10.1037/0022-006X.67.1.43

Sullivan, T. P., McPartland, T. S., Armeli, S., Jaquier, V., \& Tennen, H. (2012). Is it the exception or the rule? Daily co-occurrence of physical, sexual, and psychological partner violence in a 90-day study of substance-using, community women. Psychology of Violence, 2, 154-164. doi 10.1037/a0027106 
Suls, J., \& Fletcher, B. (1985). The relative efficacy of avoidant and nonavoidant coping strategies: A meta-analysis. Health Psychology, 4, 249-288. doi 10.1037/0278-6133.4.3.249

Tan, C., Basta, J., Sullivan, C. M., \& Davidson, W. S. (1995). The role of social support in the lives of women exiting domestic violence shelters: An experimental study. Journal of Interpersonal Violence, 10, 437-451. doi 10.1177/088626095010004004

Tedeschi, R. G., \& Calhoun, L. G. (2004). A clinical approach to posttraumatic growth. In P. Linley, S. Joseph, P. Linley, \& S. Joseph (Eds.), Positive psychology in practice (pp. 405-419). Hoboken, NJ: John Wiley.

Teyber, E., \& McClure, F. H. (2011). Interpersonal process in therapy: An integrative model. Belmont, CA: Brooks/Cole.

Thompson, L. Y., \& Snyder, C. R. (2003). Measuring forgiveness. In S. J. Lopez, C. R. Snyder, S. J. Lopez, \& C. R. Snyder (Eds.), Positive psychological assessment: A handbook of models and measures (pp. 301-312). Washington, DC: American Psychological Association. doi 10.1037/10612-019

Thompson, L. Y., Snyder, C. R., Hoffman, L., Michael, S. T., Rasmussen, H. N., Billings, L. S., . . .Roberts, D. E. (2005). Dispositional forgiveness of self, others, and situations. Journal of Personality, 73, 313-359. doi 10.1111/j.1467-6494.2005.00311.x

Tsang, J., \& Stanford, M. S. (2007). Forgiveness for intimate partner violence: The influence of victim and offender variables. Personality and Individual Differences, 42, 653-664. doi 10.1016/j.paid.2006.08.017

Williams, J., \& MacKinnon, D. P. (2008). Resampling and distribution of the product methods for testing indirect effects in complex models. Structural Equation Modeling, 15, 23-51. doi 10.1080/10705510701758166

Witvliet, C. V. O. (2003). Forgiveness. In D. G. Myers \& M. Jeeves (Eds.), Psychology through the eyes of faith (pp. 48-52). San Francisco, CA: Harper \& Row.

Yorke, N. J., Friedman, B. D., \& Hurt, P. (2010). Implementing a batterer's intervention program in a correctional setting: A tertiary prevention model. Journal of Offender Rehabilitation, 49, 456-478. doi 10.1080/10509674.2010.510770

Yuan, N. P., Koss, M. P., \& Stone, M. (2006). The psychological consequences of sexual trauma. National Online Resource Center on Violence Against Women. http://new.vawnet.org/Assoc_Files_VAWnet/AR_PsychConsequences.pdf 


\section{Author biographies}

M. Meghan Davidson, $\mathrm{PhD}$, is a counseling psychologist and associate professor at the University of Nebraska-Lincoln. She received her doctoral degree from the University of Missouri-Columbia and completed her pre-doctoral internship at the University of Oregon Counseling and Testing Center. She is a licensed psychologist. Her research interests include intimate partner violence, sexual assault, intervention, objectification, and measurement. She was the recipient of the 2014 Fritz and Linn Kuder Early Career Scientist/Practitioner Award from Division 17 of the American Psychological Association (APA).

Nicole M. Lozano, MA, is a doctoral student in the Counseling Psychology program at the University of Nebraska-Lincoln. Her research interests include intimate partner violence, sexual assault, couples, and qualitative methodology.

Brian P. Cole, $\mathrm{PhD}$, is a counseling psychologist and assistant professor at Seton Hall University. He received his doctoral degree from the University of Nebraska-Lincoln and completed his pre-doctoral internship at the University of Missouri-Kansas City Counseling Center. His research interests include positive psychology, men and masculinity, gender, and help-seeking.

Sarah J. Gervais, PhD, has a dual doctorate in psychology and women's studies from The Pennsylvania State University. She is currently an associate professor of psychology in the Law and Social Psychology programs at the University of Nebraska- Lincoln. Her research focuses on power, discrimination, objectification, and violence and is funded by the National Science Foundation. She was the recipient of the Gordon Allport Intergroup Relations Prize (Div. 9 of APA) in 2005-2006 and the Georgia Babladelis Best Paper Award (Div. 35 of APA) in 2010-2011. 